RELATIONAL COORDINATION IN SAUDI ARABIA

This is an accepted manuscript of an article published in the Journal of Nursing Management (2019), 27(4):715-721. doi: 10.1111/jonm.12735.

\author{
Linking Relational Coordination to Nurses' Job Satisfaction, Affective Commitment, and \\ Turnover Intention in Saudi Arabia \\ Rawaih Falatah RN, PhD* \\ Department of Nursing Administration and Education, College of Nursing, \\ King Saud University, Riyadh, Kingdom of Saudi Arabia \\ Email: rfalatah@ksu.edu.sa
}

Tel: + 966118051864

Edel Conway

Dublin City University Business School,

Dublin City University, Dublin, Ireland

Email: edel.conway@dcu.ie

Tel: + 35317008895

Acknowledgments: The authors would like to thank Jody Hoffer Gittell for her helpful feedback and advice during the preparation of this manuscript.

Funding: This research project was supported by a grant from the "Research Center of the

Female Scientific and Medical Colleges", Deanship of Scientific Research, King Saud University.

* Corresponding author 


\section{Linking Relational Coordination to Nurses' Job Satisfaction, Affective Commitment, and Turnover Intention in Saudi Arabia}

Aim - To examine the association between relational coordination, job satisfaction, affective commitment and turnover intention.

Background - While there is a substantial body of literature that examines how relational coordination influences outcomes among nurses in western societies, there is no known study that examines the impact of relational coordination on outcomes in a non-western healthcare system. As many of the factors associated with nursing turnover in Saudi Arabia are uniquely complex and challenging, a focus on relational coordination in this context is particularly worthy of investigation.

Method - The study utilized a cross-sectional online survey. A total of 180 nurses participated in the study.

Results - The results indicated that the relationship between relational coordination and turnover intention is mediated by job satisfaction. The results further show that the relationship between relational coordination and turnover intention is mediated by affective commitment.

Conclusion - High levels of relational coordination can give rise to various outcomes of relevance to nurses, allied health professionals, and patients.

Implications for Nursing Management - Re-configured job designs to build and cultivate links between nurses and other clinical disciplines will be necessary to enhance job satisfaction and commitment levels and to reduce turnover intention.

Key words: Relational coordination, Job satisfaction, Affective commitment, Turnover intention, Saudi Arabia 
Nurse turnover is a worldwide problem that has been linked to adverse healthcare outcomes including patient safety (Abualrub \& Alghamdi, 2012; Bae, Mark, \& Fried, 2010). Consequences associated with increased nurse turnover and turnover intention include higher patient-to-nurse ratios, a higher number of patient falls, increased pressure ulcers among patients, and lower levels of patient satisfaction (Park, Boyle, Bergquist-Beringer, Staggs, \& Dunton, 2014; Warshawsky, Rayens, Stefaniak, \& Rahman, 2013). The costs of such turnover are significant, with estimates that the loss of one nurse can cost up to 1.3 times their salary to replace (Trepanier et al., 2012).

Similar to healthcare systems around the world, the healthcare system in the Kingdom of Saudi Arabia is also negatively impacted by high levels of turnover (Falatah \& Salem, 2018). However, unlike other nations, the issue of nurse retention is even more complex because the rate of nurses in Saudi Arabia is 48.7 per 10,000 population, which is considerably lower than other nations such as the US, Japan and Canada (Almalki, FitzGerald, \& Clark, 2011; Azim \& Islam, 2018). This low rate is largely attributed to adverse attitudes towards the profession within Saudi society. For example, in a study of perceptions of the profession among high school students, Al-Omar (2004) concluded that "community image, family disagreement, cultural and communal values, long working hours, night shifts, interaction with members of the opposite gender, and the worry of not being a 'marriageable' prospect were the main reasons for not choosing nursing as a career by Saudi women" (p. 151). Thus, identifying strategies to attract and retain Saudi nationals in nursing is regarded as a key priority in the reform of the healthcare system (Almalki et al., 2011).

A number of employee-related factors such as compensation and work-life balance, and organizational factors such as organization size and design, are regarded as significant 
determinants of nurse turnover and turnover intention (Al-Ahmadi, 2014; Al-Hussami, Darawad, Saleh, \& Hayajneh, 2014). Additionally, a high level of affective commitment - characterized by a strong emotional attachment to an organization (Meyer \& Allen, 1997) - is regarded as one of the strongest negative predictors of turnover intention among nurses (Fleig-Palmer \& Rathert, 2015). A further frequently identified predictor of nurse turnover is job satisfaction (Al-Ahmadi, 2014; Alsaraireh, Quinn Griffin, Ziehm, \& Fitzpatrick, 2014; Kuo, Lin, \& Li, 2014). Evidence from Saudi Arabia suggests that job satisfaction is the most important driver of turnover (Alhusaini, 2006; Zaghloul, Al-Hussaini, \& Al-Bassam, 2008). Alhusaini (2006) found that nurse dissatisfaction was associated with poor relationships with coworkers, particularly physicians, where nurses experienced poor communication and interaction, and low levels of appreciation, respect and support. The wider literature suggests that poor communication and difficult professional relationships give rise to high levels of conflict, poor staff satisfaction, and high turnover. For example, higher levels of synergistic communication have been associated with lower turnover intention among nurses (Apker, Propp, \& Ford, 2009), while perceptions of collaboration and teamwork have been associated with higher levels of job satisfaction (Kalisch, Lee, \& Rochman, 2010).

This paper proposes that effective communication and high quality professional relationships are important organizational factors that can help in solving the issue of nurse retention. Given the particular challenges regarding coordination between nurses and core functions in Saudi Arabian healthcare, one fruitful avenue for investigating turnover intention is through an exploration of relational coordination. Gittell (2002, p. 300) defines relational coordination as "a mutually reinforcing process of communicating and relating for the purpose of task integration". The process aims to provide an explanation for the effective relational 
coordination dynamics of interdependent functional groups for the purpose of task integration, as is required within healthcare systems. Communication and relationships are the main components of relational coordination; Gittell, Seidner and Wimbush (2010) describe relational coordination as a reinforcing cycle between these two components. To be effective, communication needs to be frequent, timely, accurate, and focused on problem-solving; the underlying relationships between the functional groups need to be characterized by shared goals, shared knowledge, and mutual respect (Gittell, 2003). The theory can be most effectively generalized to organizations where there is a highly interdependent work process coupled with uncertainty and time constraints, as found in healthcare systems (Gittell, 2003). Relational coordination has been found to significantly improve job satisfaction among nurses and nurses' aids (Gittell, Weinberg, Pfefferle, \& Bishop, 2008; Havens, Vasey, Gittell, \& Lin, 2010). Two recent studies that examined the association between relational coordination, job satisfaction, work engagement, and burnout reported significant associations (Gittell et al., 2018; Havens, Gittell, \& Vasey, 2018). Both studies found that increased relational coordination is positively associated with job satisfaction and work engagement and negatively associated with burnout. This study attempts to discover new insights regarding the problem of high turnover in nursing and makes two unique contributions. First, this is the first known study that examines the association between relational coordination, affective commitment and turnover intention. Second, it considers relational coordination as a factor that will mitigate the problem of nurse turnover via its impact on levels of job satisfaction and affective commitment. While there is a substantial body of literature that examines how relational coordination influences outcomes among nurses in western societies, there is no known study that examines the impact of relational coordination on outcomes in a non-western healthcare system. As many of the factors associated 
with nursing turnover in Saudi Arabia are uniquely complex and challenging, a focus on relational coordination in this context is particularly worthy of investigation. For example, the varied multinational backgrounds of the nursing workforce in Saudi Arabia, as well as other sociocultural factors stemming from gender segregation, might interfere with effective communication and professional relationships, thereby reducing job satisfaction and commitment and contributing to higher levels of turnover intention. In addition, Saudi Arabia's culture has been described as one that is high in power distance, and one that is collectivist with the "ingroup" (e.g. family) though individualist with the out-group (e.g. guest workers) (Mellahi \& Wood, 2001). This would suggest that high levels of communication and coordination may be particularly difficult to achieve. The theory of relational coordination "makes visible the relational process underlying the technical process of coordination, arguing that coordination encompasses not only the management of interdependence between tasks but also between the people who perform those tasks". This focus on interdependence has the potential to create powerful interpersonal synergies that will strengthen bonds and enrich job satisfaction in this context. A better understanding of these relationships is critically important because high levels of turnover have the potential to disrupt continuity, working relationships and effective functioning, which can lead to both knowledge and process losses (Hancock et al., 2013). We set out to test the following hypotheses:

Hypothesis 1: The relationship between relational coordination and turnover intention will be mediated by job satisfaction.

Hypothesis 2: The relationship between relational coordination and turnover intention will be mediated by affective commitment. 


\section{Method}

The study utilized a cross-sectional online survey to examine the influence of relational coordination on job satisfaction, affective commitment, and turnover intention.

\section{Data and Sample}

An invitation containing a link to the survey was posted on six social media pages for nurses in Saudi Arabia. Individuals were informed that their participation was voluntary and that they were not required to report any personal information that would identify them. A total of 180 nurses participated in the study. The required sample size was calculated via a power analysis using G*Power 3.1®. Based on previous reports of the relationship between job satisfaction and turnover (Al-Ahmadi, 2014; Kuo et al., 2014), an effect size of $\mathrm{f}^{2}=0.06$ was considered as an appropriate conservative estimate. Thus, using the parameters of $\mathrm{f}^{2}=0.06$, with a significance level of $p=0.05$, and power of 0.80 , and nine predictors, a sample size of 133 participants was needed.

The majority of the sample was female (71\%) and from Saudi Arabia (86\%). A small proportion of the sample were Asian (14\%); the majority of which reported that they arrived in the KSA in the previous ten years $(69 \%)$, and that they were planning to leave the country within the next ten years (68\%). The average age was 33 years and the average years of nursing experience was 10 years. Half of the sample (50\%) held a Bachelor of Science in Nursing (BSN) degree. Most respondents also reported their Saudi Commission for Health Specialties rank, which ranged from nurse technician to nurse consultant, as specialist. 


\section{Measures}

The scales used in this study included relational coordination, job satisfaction, affective commitment, turnover intention, and demographics.

\section{Turnover Intention.}

Turnover intention was measured using the six-item Roodt (2004) turnover intention scale (TI-6). The six items were rated using three types of semantic differential scales ranged between one and five with different anchors $(1=$ never, $5=$ always; $1=$ to no extent, $5=$ to a very large extent; 1 = highly unlikely, 5 = highly likely). A sample item is "How likely are you to accept another job at the same compensation level should it be offered to you. The reliability of the scale was 0.70 .

Job Satisfaction.

Job satisfaction was measured using The McCloskey/Mueller Satisfaction Scale (MMSS), which was designed for nurses working in a clinical setting (Mueller \& McCloskey, 1990). This scale has 31 items and asks respondents to rate their satisfaction with various aspects of their jobs including opportunities for social contact, control over working conditions, salary and flexibility. Responses to the items range from 'very dissatisfied' (1) to 'very satisfied' (5). The reliability of the scale was 0.94 .

\section{Affective Commitment.}

Affective commitment was measured using the six-item scale developed by Meyer, Allen, and Smith (1993). A sample item was "I would be happy to spend the rest of my career with this organisation". Participants rated their agreement with each statement on a 7-point Likert-type scale $(1=$ strongly disagree, $7=$ strongly agree $)$. The reliability of the scale was 0.84 . 


\section{Relational Coordination.}

Gittell's (2012) seven-item scale was used to measure relational coordination. Responses were based on a 5-point scale ranging from low to high with different anchors depending on the item. In this self-administrated scale, the participants were asked to report the behaviors of others instead of reporting their own behavior in order to decrease the likelihood of socially desirability bias (Gittell, 2012). Relational coordination is an individual-level measure that evaluates the connection between an individual respondent and others (Gittell, 2012). Four of the items focus on communication, evaluating its frequency, timeliness, accuracy, and its focus on problem solving. Three items measure professional relationships, evaluating the strength of relationships based on shared goals, shared knowledge, and mutual respect. The reliability of the scale was 0.87 .

\section{Ethics}

The study was approved by the Saudi Ministry of Health and the University of Massachusetts Amherst institutional review boards.

\section{Data Analysis}

Data were analyzed using SPSS (v. 24) and the hypotheses were tested using Hayes' (2013) PROCESS macro for mediation.

\section{Findings}

Table 1 presents the means, standard deviations and inter-correlations for all variables. 
Insert Table 1 about here

Hypothesis 1 posited that the relationship between relational coordination and turnover intention would be mediated by job satisfaction. The results indicated a statistically significant direct relationship between relational coordination and turnover intention $(\mathrm{F}(1,129)=9.99, \mathrm{p}<.01$, $\left.R^{2}=.07 ; \beta=-1.46, \mathrm{t}(129)=-3.16, \mathrm{p}<.01\right)$. They also showed that there was a significant relationship between relational coordination and job satisfaction $(\mathrm{F}(1,129)=63.06, \mathrm{p}<.001$, $\left.\mathrm{R}^{2}=.33 ; \beta=.585, \mathrm{t}(129)=7.94, \mathrm{p}<.001\right)$. The overall mediated model was significant $(\mathrm{F}(1$, $\left.128)=12.89, \mathrm{p}=.01, R^{2}=.1677\right)$ and showed that when job satisfaction was added to the model $(\beta=-2.01, \mathrm{t}(128)=-.3 .84, \mathrm{p}<.01)$, the relationship between relational coordination and turnover intention was no longer significant $(\beta=-.281, \mathrm{t}(128)=-5.25, \mathrm{p}>.05)$. Bootstrapping results for the indirect effect interval (95\% confidence) is between -1.91 and -.597 , and because it does not cover 0, additional support is provided for the mediated effect. This supports hypothesis 1 .

Insert Figure 1 about here

Hypothesis 2 proposed that the relationship between relational coordination and turnover intention would be mediated by affective commitment. The results for this model showed a statistically significant direct relationship between relational coordination and turnover intention 
$\left(\mathrm{F}(1,131)=7.97, \mathrm{p}=.01, R^{2}=.06, \beta=-1.35, \mathrm{t}(131)=-.2 .82, \mathrm{p}<.01\right)$. They also showed that there was a significant relationship between relational coordination and affective commitment $(\mathrm{F}$ $\left.(1,131)=28.62, \mathrm{p}<.001, R^{2}=.18, \beta=.68, \mathrm{t}(131)=5.35, \mathrm{p}<.001\right)$. The overall mediated model was significant $\left(\mathrm{F}(1,130)=18.13, \mathrm{p}=.001, R^{2}=.22\right)$ and showed that when affective commitment was added to the model $(\beta=-1.55, \mathrm{t}(130)=-.5 .17, \mathrm{p}<.001)$, the relationship between relational coordination and turnover intention was no longer significant $(\beta=-.29, \mathrm{t}$ $(130)=-.61, p>.05$. Bootstrapping results for the indirect effect interval (95\% confidence) is between -1.72 and -.540 , and because it does not cover 0 , additional support is provided for the mediated effect. Thus, hypothesis 2 is supported.

Insert Figure 2 about here

\section{Discussion}

This study set out to better understand the role that relational coordination plays in influencing turnover intention among nurses in a Saudi Arabian context. It represented the first known study to link relational coordination and affective commitment to turnover intention, a problem that is endemic within healthcare organizations worldwide. A better understanding of turnover intention is critically important because high levels of turnover have the potential to disrupt continuity, working relationships and effective functioning, which can lead to both knowledge and process losses (Hancock et al., 2013). The findings reveal that relational coordination plays an important role in influencing both job satisfaction and affective commitment, which in turn influence 
turnover intention. These findings support previous findings that have reported similar relationships between relational coordination and job satisfaction (Gittell, Weinberg, Pfefferle, \& Bishop, 2008; Gittell et al., 2018; Havens, Gittel, \& Vasey, 2018; Havens, Vasey, Gittell, \& Lin, 2010). However, they extend on these findings by suggesting that relational coordination plays an important role in enhancing both job satisfaction and affective commitment, which act as important mechanisms in reducing turnover intention. The study therefore makes an important contribution to understanding how relational coordination - as characterized by frequent, timely and accurate communication, shared goals, shared knowledge, and mutual respect - is important in fostering an emotional attachment to the organization in the form of affective commitment, and in fostering job satisfaction, which in turn can lower intention to leave. The findings therefore support existing evidence suggesting that relational coordination as a construct is highly relevant within organizations where there exist highly interdependent work processes coupled with uncertainty and time constraints, as found in healthcare systems (Gittell, 2003). The findings extend on these findings as they indicate that the positive outcomes associated with relational coordination can be further generalized to non-western settings such as Saudi Arabia. Although there are differences between the western and Saudi Arabian social-organizational contexts, both share common characteristics including, for example, the features of departmentalization and specialization. The healthcare system in Saudi Arabia, like other healthcare systems around the world, is operated by a number of different professions aiming to achieve one goal i.e. high-quality care outcomes. Our findings suggest that the maintenance of effective communication and coordination among healthcare professional groups, which cultivate shared knowledge and goals and mutual respect can positively influence satisfaction and commitment and in doing so can lower intention to leave. This is a particularly important 
finding given the high power distance in Saudi Arabian work contexts (Mellahi \& Wood, 2001) and potential challenges in achieving high levels of relational coordination, particularly between potential 'out groups' e.g. individuals of different nationalities or functional disciplines.

\section{Implications for Nursing Management}

The findings have a number of important implications for practice. First, they suggest a number of routes through which relational coordination can reduce turnover intention. This might include the introduction of re-configured job designs and performance management systems that place greater emphasis on cross-functional teams engaging regularly in interactions to solve problems in order to positively impact on relevant outcomes. Such inter-disciplinary teamworking may serve to address the tension that is reported to exist between higher-level medical personnel (i.e. physicians) and nurses and allied professionals (Apker et al., 2009). While doctors do make independent decisions regarding patient care, nurses depend on a high level of coordination with other allied professionals, and therefore represent important 'linchpins' in connecting lower level functions and processes to higher-level decisions. As such, they can act as the 'glue' that either binds these activities, decisions and people together, or that potentially disrupts them should they choose to leave. This suggests that re-configured job designs to build and cultivate links between nurses and other clinical disciplines will be necessary to enhance job satisfaction and commitment levels and to reduce turnover intention. This can be achieved through the establishment of frequent and timely multi-disciplinary team meetings that will encourage more accurate knowledge exchange (and thereby enhance mutual knowledge), better goal alignment, less process losses and more effective problem solving 
among inter-disciplinary teams. These activities will serve to positively influence work-related outcomes relevant to nurses, but also those of other professionals and patients.

\section{Limitations}

The study has some limitations. First, the study was cross-sectional which limits the extent to which inferences regarding causality can be made. Second, the study assessed only nurses' perceptions of relational coordination rather than perceptions from a wider range of disciplines and roles. In addition, a convenience sample was used which presents the possibility of selfselection bias and which may not be representative of the nursing population in general. For these reasons, the generalizability of the findings may be limited. Third, the data were obtained through self-reported surveys and though respondents were assured of confidentiality and anonymity, the potential for common method bias cannot be entirely ruled out. Fourth, the sample was predominately female and, while this is representative of nursing roles in general, the levels of relational coordination reported may be reflect the tendency for females to be more sensitive to social cues and more cooperative than men (Croson \& Gneezy, 2009). Future research involving longitudinal research designs and a broader range of health care providers and occupations is therefore recommended.

\section{Conclusion}

This study set out to better understand how high levels of turnover among nurses can be mitigated through enhanced levels of relational coordination. Our findings show that perceptions of relational coordination influence nurses' turnover intentions via their effects on both job satisfaction and affective commitment. The findings suggest that high levels of relational 
coordination - achieved through re-configured job designs, performance management, and frequent cross-disciplinary meetings - can give rise to various outcomes of relevance to nurses, allied health professionals, and patients. 


\section{References}

Abualrub, R.F., \& Alghamdi, M.G. (2012). The impact of leadership style on nurses' satisfaction and intention to stay among Saudi nurses. Journal of Nursing Management, 20(5), 668-678 doi: 10.1111/j.1365-2834.2011.01320.x.

Al-Ahmadi, H. (2014). Anticipated nurses' turnover in public hospitals in Saudi Arabia. The International Journal of Human Resource Management, 25(3), 412-433.

Doi: $10.1080 / 09585192.2013 .792856$

Alhusaini H. (2006). Obstacles to the efficiency and performance of Saudi nurses at the Ministry of Health, Riyadh Region: Analytical field study. Riyadh: Ministry of Health.

Al-Hussami, M., Darawad, M., Saleh, A., \& Hayajneh, F. A. (2014). Predicting nurses' turnover intentions by demographic characteristics, perception of health, quality of work attitudes. International Journal of Nursing Practice, 20(1), 79-88. doi:10.1111/ijn.12124

Almalki, M., FitzGerald, G., \& Clark, M. (2011). The nursing profession in Saudi Arabia: an overview. International Nursing Review, 58(3): 304-311. doi: 10.1111/j.14667657.2011.00890.x.

Al-Omar, B. A. (2004). Knowledge, attitudes and intention of high school students towards the nursing profession in Riyadh city, Saudi Arabia. Saudi Medical Journal, 25(2), 150-155.

Apker, J., Propp, K.M., \& Ford, W.S. (2009). Investigating the effect of nurse-team communication on nurse turnover: Relationships among communication processes, identification, and intent to leave. Health Communication, 24(2), 106-14. doi: 10.1111/j.1547-5069.2009.01319.x.

Alsaraireh, F., Quinn Griffin, M. T., Ziehm, S. R., \& Fitzpatrick, J. J. (2014). Job satisfaction and turnover intention among Jordanian nurses in psychiatric units. International Journal of 
Mental Health Nursing, 23(5), 460-467. doi:10.1111/inm.12070

Azim, M.T., \& Islam, M.M. (2018). Social support, religious endorsement, and career commitment: A study on Saudi nurses. Behavioral Science, 8(1), 1-13. 10.3390/bs8010008

Bae, S.H., Mark, B., \& Fried, B. (2010). Impact of nursing unit turnover on patient outcomes in hospitals. Journal of Nursing Scholarship, 42(1): 40-9.

Croson, R., \& Gneezy, U. (2009). Gender differences in preferences. Journal of Economic Literature, 47(2), 448-74. doi:10.1257/jel.47.2.1

Falatah, R., \& Salem, O.A. (2018). Nurse turnover in the Kingdom of Saudi Arabia: An integrative review. Journal of Nursing Management, 26, 630-638. doi: 10.1111/jonm.12603.

Fleig-Palmer, M.M., \& Rathert, C. (2015). Interpersonal mentoring and its influence on retention of valued health care workers: the moderating role of affective commitment. Health Care Management Review, 40, 573-603. doi: 10.1097/HMR.0000000000000011

Gittell, J.H. (2002). Relationships between service providers and their impact on customers. Journal of Service Research, 14, 299-310.

Gittell, J. H. (2003). The Southwest Airlines Way: Building Relationships For High Performance. New York: McGraw-Hill.

Gittell, J. H. (2012). Relational coordination: Guidelines for theory, measurement and analysis. Waltham, MA: Brandeis University.

Gittell, J. H., Weinberg, D., Pfefferle, S., \& Bishop, C. (2008). Impact of relational coordination on job satisfaction and quality outcomes: a study of nursing homes, Human Resource Management Journal, 18, 154-171.

Gittell, J. H., Seidner, R., \& Wimbush, J. (2010). A Relational model of how high-performance work systems work. Organization Science, 21, 490-506. doi:10.1287/orsc.1090.0446 
Gittell, J. H., Logan, C., Cronenwett, J., Foster, T. C., Freeman, R., Godfrey, M., \& Vidal, D. C. (2018). Impact of relational coordination on staff and patient outcomes in outpatient surgical clinics. Health Care Management Review, 44(4). doi:10.1097/HMR.0000000000000192

Hancock, J.I., Allen, D.G., Bosco, F.A., McDaniel, K., \& Pierce, C.A. (2013). Meta-analytic review of employee turnover as a predictor of firm performance. Journal of Management, 39, 573-603. doi: $10.1177 / 0149206311424943$

Havens, D.S., Vasey, J., Gittell, J.H., \& Lin, W.T. (2010). Relational coordination among nurses and other providers: Impact on quality of patient care. Journal of Nursing Management, 18, 926-37. doi: 10.1111/j.1365-2834.2010.01138.x.

Havens, D. S., Gittell, J. H., \& Vasey, J. (2018). Impact of relational coordination on nurse job satisfaction, work engagement and burnout: Achieving the quadruple aim. Journal of Nursing Administration, 48, 132-140. doi:10.1097/NNA.0000000000000587

Hayes, Andrew F. (2013). Introduction to mediation, moderation, and conditional process analysis: A regression-based approach. New York, NY: The Guilford Press.

Kalisch, B.J., Lee, H., \& Rochman, M. (2010). Nursing staff teamwork and job satisfaction. Journal of Nursing Management, 18(8), 938-47. doi: 10.1111/j.1365-2834.2010.01153.x.

Kuo, H.-T., Lin, K.-C., \& Li, I.-C. (2014). The mediating effects of job satisfaction on turnover intention for long-term care nurses in Taiwan. Journal of Nursing Management, 22(2), 22533. doi:10.1111/jonm.12044

Mellahi, K., \& Wood, G. (2001) 'HRM in Saudi Arabia'. In P. Budhwar, \& Y. Debrah (eds.) Human resource management in developing countries. London: Routledge, pp. 135-52 
Meyer, J., \& Allen, N. (1997). Commitment in the workplace: Theory, research, and application. Thousand Oaks, CA: Sage Publications.

Meyer, J.P., Allen, N.J., \& Smith, C.A. (1993). Commitment to organizations and occupations: Extension and test of a three-component conceptualization. Journal of Applied Psychology, 78, 538-551. doi: 10.1037/0021-9010.78.4.538

Mueller, C.W., \& McCloskey, J.C. (1990). Nurses' job satisfaction: a proposed measure. Nursing Research, 39, 113-7.

Park, S. H., Boyle, D. K., Bergquist-Beringer, S., Staggs, V. S., \& Dunton, N. E. (2014). Concurrent and lagged effects of registered nurse turnover and staffing on unit-acquired pressure ulcers. Health Services Research, 49, 1205-1225. doi:10.1111/1475-6773.12158

Roodt, G. (2004). Turnover intentions. Unpublished document. Johannesburg: University of Johannesburg.

Trepanier, S., Early, S., Ulrich, B. , Cherry, B. (2012). New graduate nurse residency program: A cost-benefit analysis based on turnover and contract labor usage. Nursing Economics, 30, 207-14.

Warshawsky, N., Rayens, M. K., Stefaniak, K., \& Rahman, R. (2013). The effect of nurse manager turnover on patient fall and pressure ulcer rates. Journal of Nursing Management, 21, 725-732. doi:10.1111/jonm.12101

Zaghloul, A.A., Al-Hussaini, M.F., \& Al-Bassam, N.K. (2008). Intention to stay and nurses’ satisfaction dimensions. Journal of Multidisciplinary Healthcare, 1, 51-8. 


\section{Table 1 Descriptive Statistics}

\begin{tabular}{|c|c|c|c|c|c|c|c|c|c|c|}
\hline Variables & Mean & SD & 1. & 2. & 3. & 4. & 5. & 6. & 7. & 8. \\
\hline 1. Turnover intention & 3.08 & .75 & & & & & & & & \\
\hline 2. Affective commitment & 4.28 & 1.27 &.- & & & & & & & \\
\hline 3. Job satisfaction & 3.03 & .82 & $\begin{array}{c}- \\
.407^{* * *}\end{array}$ & $.449^{* * *}$ & & & & & & \\
\hline 4. Relational coordination & 2.85 & .80 & $-.240^{* *}$ & $.398^{* * *}$ & $.566^{* * *}$ & & & & & \\
\hline 5. Gender $(2=$ female $)$ & 1.77 & .42 & -.073 & .026 & .073 & $.201^{* * *}$ & & & & \\
\hline 6. Age (years) & 32.94 & 5.69 & -.138 & .134 & .161 & .099 & $.216^{* *}$ & & & \\
\hline 7. Nursing experience (years) & 10.31 & 6.33 & -.069 & .139 & .156 & .030 & $-.170^{*}$ & $.845^{* * *}$ & & \\
\hline $\begin{array}{l}\text { 8. Educational attainment (1=diploma, } 6 \\
=\mathrm{PhD})\end{array}$ & 2.44 & 1.08 & .148 & .053 & .084 & .048 & -.040 & .057 & -.066 & \\
\hline 9. Nationality $(2=$ Saudi) & 1.29 & .70 & $-.173^{*}$ & $.265^{* *}$ & $.308^{* * * *}$ & $.322^{* * * *}$ & $.181^{*}$ & $.171^{*}$ & .138 & $.158^{*}$ \\
\hline
\end{tabular}

${ }^{*} \mathrm{p}<.05 . * * \mathrm{p}<.01 . * * * \mathrm{p}<.001$. 
Figure 1. Job satisfaction as a mediator of the relationship between relational coordination and turnover intention

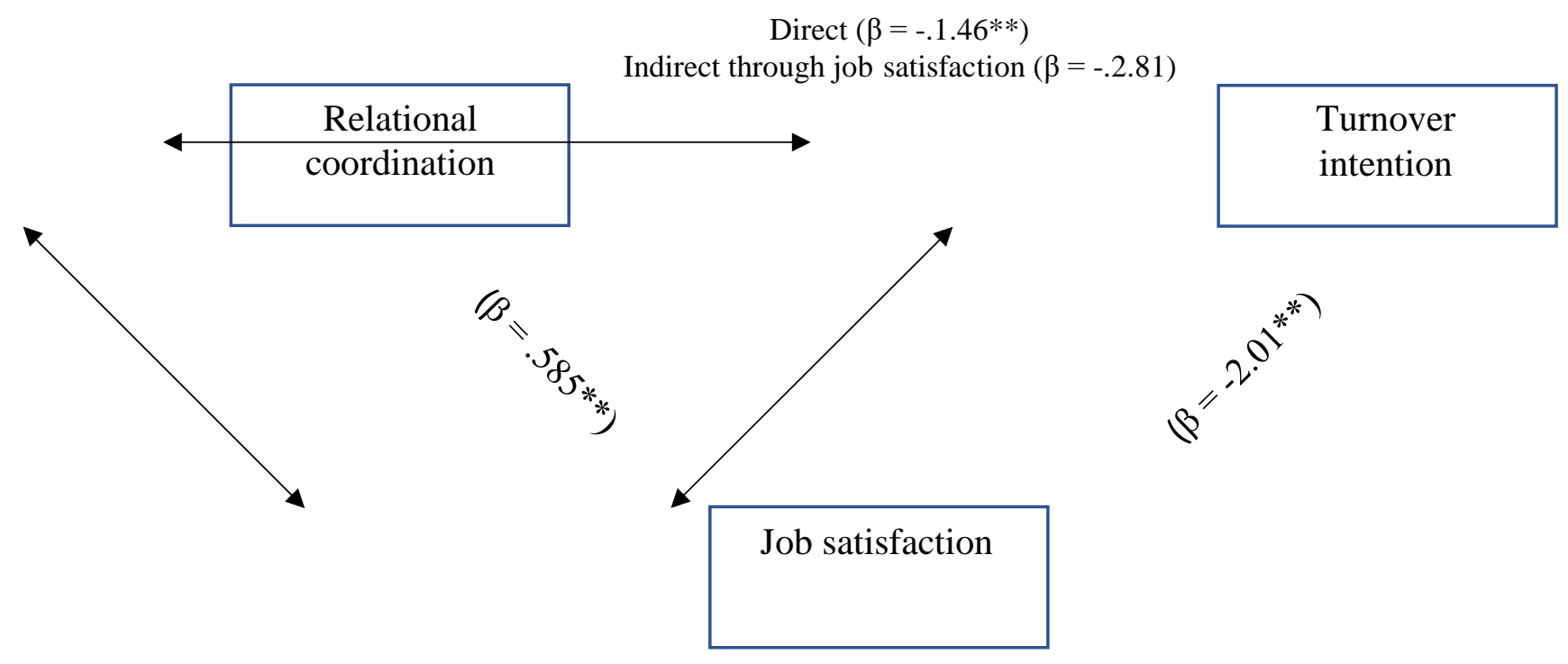

$* \mathrm{p}<.05 . * * \mathrm{p}<.01 . * * * \mathrm{p}<.001$. 
Figure 2. Affective Commitment (AC) as a mediator of the relationship between relational coordination and turnover intention

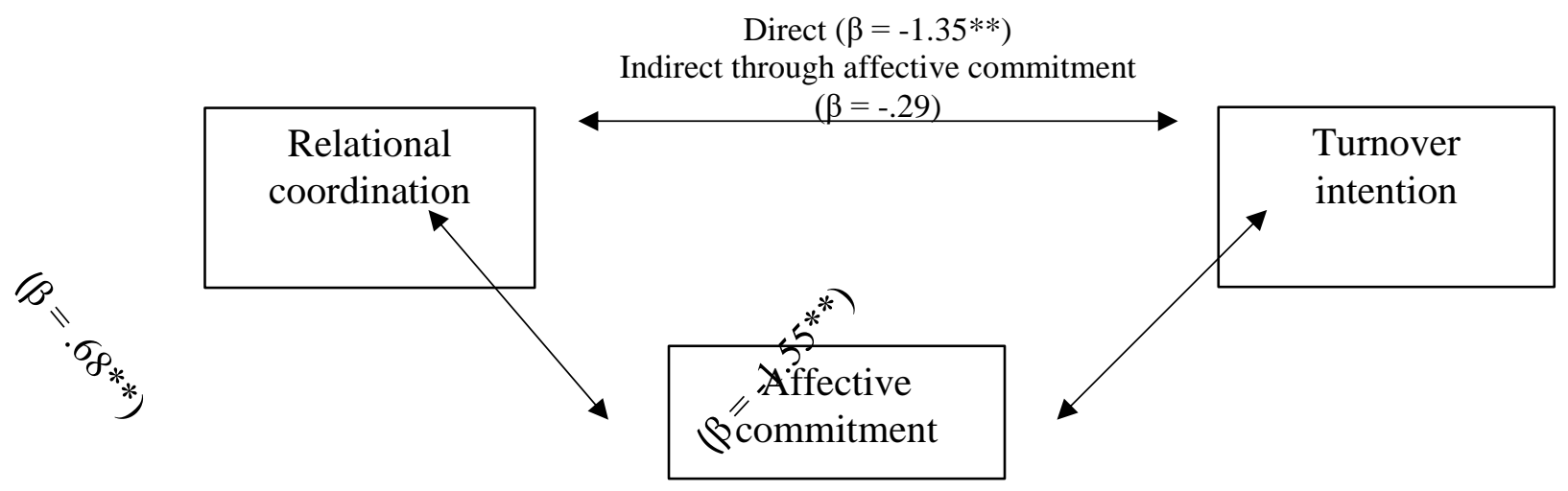

$* \mathrm{p}<.05 . * * \mathrm{p}<.01 . * * * \mathrm{p}<.001$ 